\section{Exploring the role of self-esteem and parenting patterns on alcohol use and abuse among adolescents}

\section{Franklin N. Glozah}

Department of Psychology and Human Development, Regent University College of Science and Technology, Accra, Ghana

\section{Abstract}

The type of parental child-rearing practices used by parents and guardians substantially influence children's self-esteem and consequently their decision to engage in alcohol use, its abuse. The aim of this study was to explore the role of self-esteem and parenting patterns on alcohol use and abuse among adolescents. Three hundred and sixteen boys and girls in Senior High Schools completed selfreport questionnaires assessing self-esteem, parenting patterns and alcohol use and abuse. The results showed that while girls reported lesser self-esteem than boys, boys reported higher levels of alcohol use and abuse than girls. Also, authoritative parenting pattern had a positive effect on self-esteem and a negative effect on alcohol use. On the other hand, authoritarian and permissive parenting patterns had negative effects on self-esteem and positive effects on alcohol use, with slight variations. These results provide valuable information regarding strategies aimed at fostering parent-child relationship and rapport with the ultimate aim of bolstering the self-esteem of adolescents to subsequently eschew insalubrious behaviour, particularly alcohol use and abuse.

\section{Introduction}

Alcohol use, and indeed, its abuse is one of the commonest maladaptive lifestyles that adolescents engage in during adolescents. ${ }^{1}$ Harmful alcohol consumption (or alcohol abuse or alcoholism) is a psychiatric diagnosis describing the recurring use of alcoholic beverages despite negative consequences - a pattern of drinking that result in harm to an individual's health, interpersonal relationships, or ability to work. ${ }^{2}$ Alcohol abuse may lead to failure to fulfil responsibilities at work, school or home; drinking in dangerous situations; legal problems associated with alcohol use; and continued drinking despite problems that are caused or worsened by drinking. ${ }^{3}$ If not properly supervised during upbringing, adolescents may adopt maladaptive habits and lifestyles that could be detrimental to their health and wellbeing. When up-bringing or supervision is done by parents, the type of parenting patterns or style practiced could substantially affect the psychosocial development of children and adolescents, resulting among others, in the use or abuse of alcohol. ${ }^{4}$ The concept of parenting pattern is used to represent normal variations in parents' attempts to control and socialise their children, 5 by considering i) parental responsiveness - the extent to which parents intentionally foster individuality, self-regulation, and self-assertion by being attuned, supportive, and acquiescent to children's special needs and demands and ii) parental demandingness - the claims parents make on children to become integrated into the family as a whole, by their maturity demands, supervision, disciplinary efforts and willingness to confront the child who disobeys. ${ }^{6}$ Salient within the various categorisation of parenting styles is the delineation into authoritative, authoritarian, and permissive styles of parenting, albeit adolescents mostly report authoritative and authoritarian patterns. ${ }^{7}$ The authoritative style involves a combination of warmth, demandingness and democracy, where the style of parenting progresses as the child grows older, such that children find increasing levels of autonomy within the family as knowledge and competence increases, ${ }^{8}$ the tendency of alcohol-use is thus more likely to be lower as the child may feel confident enough to ask or talk about alcohol with parents who will in turn advise on the harmful effects of alcohol use and abuse.

The authoritarian pattern on the other hand is grounded in the believe that the dominant mode of interaction is control on children that is sustained into adolescence and adulthood and decision making is an ideology enforced often at the expense of children who are not equal to the task of participating, ${ }^{9}$ the likelihood of consuming alcohol may thus be higher as this decision will lie entirely with parents. By deduction, authoritarian parenting pattern may be construed as a form of parental overprotection and this has been found to have the strongest relationship to regular alcohol use, whereby adolescents who perceived more parental overprotection were at increased risk of developing regular alcohol use. ${ }^{10}$ Permissive parenting, in-between, involves less parental restrictions and control on children, who are expected to regulate their own activities without much interference from their parents, ${ }^{11}$ the likelihood to initiate alcohol use or abuse may also be higher due to the laxity of this parenting pattern. The lowest prevalence of adolescent use of alcohol was found for those who reported that both parents practiced an authoritative parenting pattern. ${ }^{12}$ Also, adolescents whose parents were authoritative were found to be less likely to drink heavily than adoles-
Correspondence: Franklin N. Glozah, Department of Psychology and Human Development, Regent University College of Science and Technology. P. 0. Box 1636, Dansoman, Accra, Ghana.

Tel: +233.302 .662885$

E-mail: franklin.glozah@regent.edu.gk

Key words: parenting patterns, self-esteem, adolescents, alcohol use, alcohol abuse.

Acknowledgments: Many thanks to Oneil Ocansey, Emmanuel Yeboah Djan, Mawusi Glozah and Samuel Doudo for their assistance in data collection. My sincere gratitude goes to the school authorities for granting permission for this study to be carried out in their schools. Of course, without the students who took time off their lessons to complete questionnaires this study would not have been possible, thank you all.

Conflict of interests: the author declares no potential conflict of interests.

Received for publication: 29 August 2013.

Revision received: 19 September 2013.

Accepted for publication: 24 September 2013.

This work is licensed under a Creative Commons Attribution NonCommercial 3.0 License (CC BYNC 3.0).

(C) Copyright F.N. Glozah, 2014

Licensee PAGEPress, Italy

Health Psychology Research 2014; 2:1898

doi:10.4081/hpr.2014.1898

cents from the other two parenting patterns. ${ }^{9}$

Besides the influence parenting patterns have on alcohol use and abuse, self-esteem has been widely reported to be a major precipitating factor in alcohol use or abuse during adolescence. While a high percentage of adolescents become involved as a part of peer pressure and socialisation, many grow to depend on alcohol-use to fill a personal void i.e. low self-esteem. ${ }^{13}$ Self-esteem is basically a person's overall evaluation or appraisal of his or her own worth - the conscious reflection of one's own being or identity, as an object separate from others or from the environment. ${ }^{14}$ Individuals with high self-esteem are characterized by tolerance and respect for others, accept responsibility for their actions, take pride in their accomplishment, are self-motivated, capable of handling criticism, seek challenges and stimulation of worthwhile and demanding goals and take command and control of their lives. ${ }^{15}$ Findings suggest that individuals with low self-esteem may unintentionally drink as a means to regulate unfulfilled needs for acceptance, and people with high self-esteem may drink as a means to enhance positive interpersonal relationships. ${ }^{16}$ Accordingly, a negative and significant rela- 
tionship was found between the quantity of drinks consumed on a typical day and selfesteem of secondary school students. ${ }^{17}$

The role of self-esteem and parenting patterns on alcohol use and abuse during adolescents has received little or no attention in Ghana. In fact, there is a paucity of extant literature that has explored the interrelationships among self-esteem, parenting patterns and alcohol use among adolescents. Given the family-cultural setting in Ghana, where childrearing may be undemocratic and alcohol is used for prominent social events such as naming ceremonies and engagements, it is expected that this would influence adolescents alcohol use given that parents openly participate in these socially acceptable ceremonies. The purpose of this study therefore is to explore the role self-esteem and parental patterns play in the use and abuse of alcohol in adolescents. From the foregoing, it is pertinent and germane to depict the association between selfesteem, parenting patterns and alcohol use and abuse in the conceptual/hypothesised model in Figure 1.

\section{Materials and Methods}

\section{Participants and procedure}

Three hundred and sixteen boys and girls were randomly selected from six urban Senior High Schools (SHS) in Accra to participate in the study. Their ages range from 13 to 22 years old. Participants below the age of 18 were given an additional parental consent form for their parent or guardian to sign. In each school classrooms were randomly selected from the list of all classrooms in the school, and on the days of data collection any student in any of the randomly selected classrooms with a signed consent form and willing to participate was allowed to complete the questionnaires in their respective classrooms. Ethical approval was obtained from the Research Ethics Board, Regent University College of Science and Technology, Ghana. Each SHS head gave permission for their schools and students to participate in the study.

\section{Measures}

A self-report cross-sectional design was used essentially involving the completion of questionnaires on demographic characteristics i.e. gender, class/form, age, and parents' level of education as well as parenting patterns, self-esteem and alcohol use and abuse.

\section{Parental authority questionnaire}

The Parental Authority Questionnaire (PAQ) ${ }^{18}$ was used to assess parenting patterns. The PAQ was developed as a self-report measure for adolescents to respond to questions concerning how their parents relate with them. The
PAQ consists of 30 items, 10 each, for the three different styles of parenting in a 5-point scale (1 $=$ strongly disagree to $5=$ strongly agree), with higher scores indicating the dominance of each of the particular parenting style. The PAQ seeks views with items such as as I was growing up my parents did not allow me to question any decision they had made and as I was growing up my parents often told me exactly what they wanted me to do and how they expected me to do it. The reliability of the PAQ was found to be $\alpha=0.77$ to 0.92 in a test re-test check over a twoweek period. 18 The reliability of the PAQ in the present sample is $\alpha=0.78,0.86$ and 0.74 for the authoritarian, authoritative and permissive patterns respectively.

\section{Rosenberg self-esteem scale}

The Rosenberg Self-Esteem Scale (RSES) ${ }^{14}$ was used to assess self-esteem. The RSES is a ten-item inventory which consists of five positive and five negative items answered on a four point scale with the response format ranging from strongly agree (3) to strongly disagree (0). Higher scores indicate higher selfesteem. It has items such as on the whole, I am satisfied with myself and at times, I think I am no good at all. An internal consistency reliability ranging from 0.85 to 0.88 was found. ${ }^{14} \mathrm{~A}$ reliability of 0.88 has also been reported.19 In the present sample a reliability coefficient $\alpha=0.83$ was found.

\section{Alcohol use disorder identification test}

The alcohol use disorder identification test (AUDIT) ${ }^{20}$ was used to assess alcohol use and abuse. The AUDIT is comprised of ten items developed to determine if a person's alcohol consumption may be harmful. Questions relate to alcohol consumption, alcohol dependence and alcohol related problems. Response options range from never (0) to daily or almost daily (4), with high scores indicating a possible alcohol use disorder. The AUDIT was developed and evaluated over a period of two decades, and it has been found to provide an accurate measure of risk across gender, age, and cultures. ${ }^{20} \mathrm{~A}$ test-retest reliability study indicated high correlation coefficient $r=0.86 .21$ The Cronbach's alpha in the present sample is $\alpha=0.92$.

\section{Statistical analysis}

The Statistical Package for Social Sciences (SPSS) version 21 was used for the initial statistical analysis. Independent samples t-tests were used to assess gender differences in selfesteem and gender differences in alcohol use and abuse. Full Information Maximum

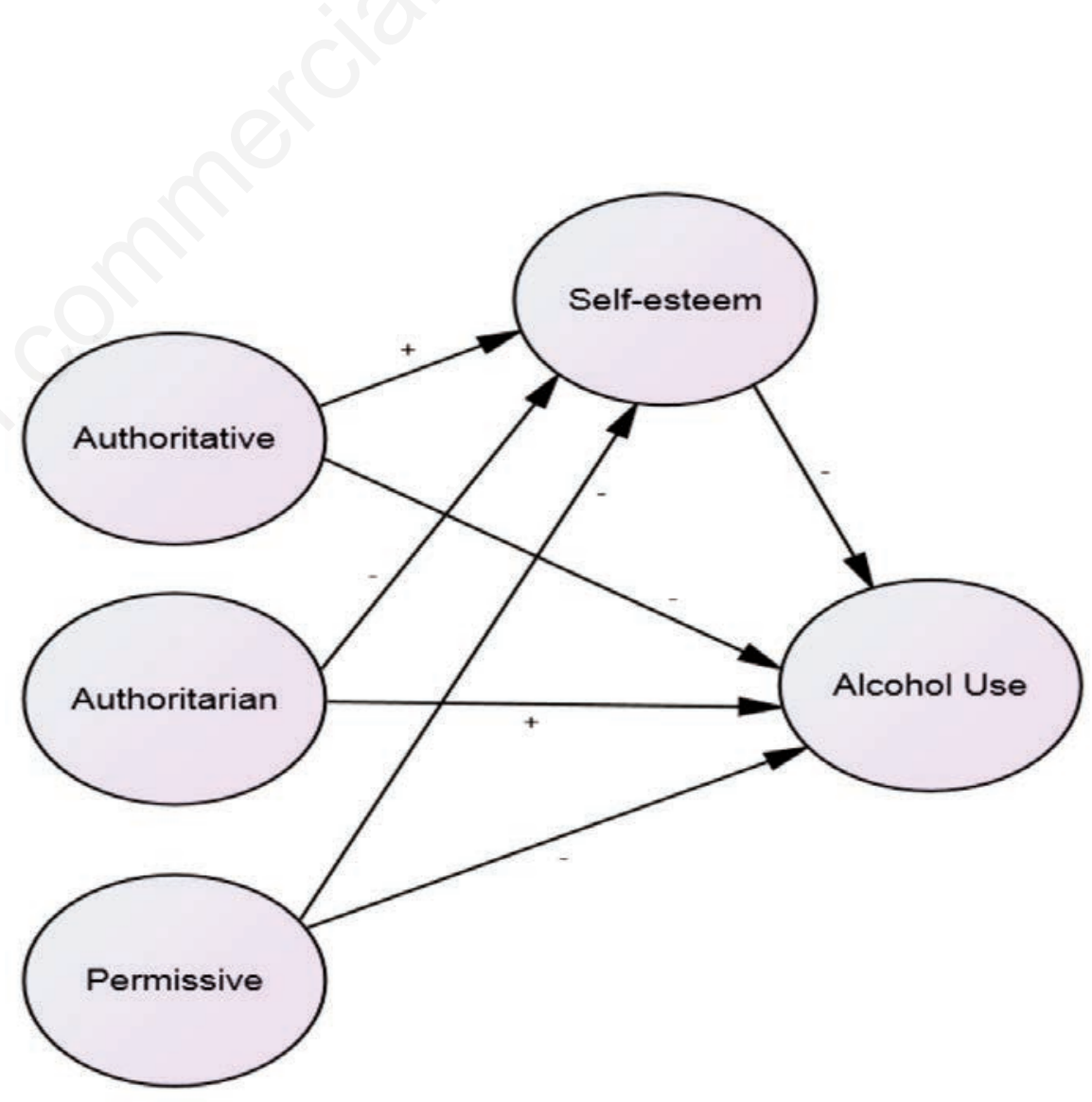

Figure 1. Hypothesised model. 
Likelihood (FIML) estimation method was used in IBM SPPS AMOS 21 software to conduct a Structural Equation Modelling (SEM) which explored the interrelationships among self-esteem, parenting patterns and alcohol use and abuse. The Root Mean Square Error of Approximation (RMSEA) was the main evaluation criteria used to evaluate goodness of fit. Also, the Tucker-Lewis Index (TLI), Comparative Fit Index (CFI), chi square degrees of freedom ratio ( $\chi^{2} / \mathrm{df}$ ), chi square $\left(\chi^{2}\right)$ goodness-of-fit statistic, and the evaluation of parameter estimates were used. RMSEA cut-off values $\leq 0.05$ indicate a good fit although values ranging from 0.06 to 0.08 also indicate acceptable fit. CFI and TLI cut-off values range from 0 to 1 with values closer to 1 indicating good fit. The smaller the $\chi^{2}$ goodness-of-fit statistic, the better the fit, with value zero indicating perfect fit and a value with $\chi^{2}(\mathrm{P}>0.05)$ indicating acceptable fit. Chi square degrees of freedom ratio ( $\chi^{2 / \mathrm{df}}$ ), (or CMIN/DF), specifies the ability of the hypothesised model to fit the sample data. Values less or equal to 2 indicate a good fit. ${ }^{22}$ The statistical significance of all parameter estimates were evaluated at the 0.05 level.

Table 1. Demographic characteristics of participants.

\begin{tabular}{lc} 
Demographics & N. (\%) \\
Age & \\
13 & $4(1.3)$ \\
14 & $24(7.6)$ \\
15 & $52(16.5)$ \\
16 & $98(31.0)$ \\
17 & $93(29.4)$ \\
18 & $32(10.1)$ \\
19 & $8(2.5)$ \\
20 & $2(0.6)$ \\
21 & $2(0.6)$ \\
22 & $1(0.3)$ \\
Gender & \\
Male & $176(55.7)$ \\
Female & $140(44.3)$ \\
\hline Class/form & \\
One & $97(30.7)$ \\
Two & $114(36.1)$ \\
Three & $105(33.2)$ \\
Mothers highest education attained & \\
No education & $3(0.9)$ \\
Basic School & $106(33.5)$ \\
Secondary School & $154(48.7)$ \\
Polytechnic/Training College & $32(10.1)$ \\
University & $21(6.6)$ \\
\hline Fathers highest education attained & \\
No education & $0(0)$ \\
Basic School & $83(26.3)$ \\
Secondary School & $96(30.4)$ \\
Polytechnic/Training College & $121(38.3)$ \\
University & $68(21.5)$ \\
\hline & \\
\hline & \\
\hline
\end{tabular}

\section{Results}

\section{Demographic characteristics}

It can be observed from Table 1 that majority of the participants were males and between 16 and 17 years old, with almost equal representation from each of the classes/forms. Secondary education and University level education is the most reported highest level of education attained by mothers and fathers respective. 0 n the other hand only three participants reported that their mothers have no education at all while none reported 'no education' for fathers.

\section{Gender differences in self-esteem} and alcohol use and abuse

Table 2 shows gender differences in selfesteem and alcohol use and abuse. It can be observed that boys reported more self-esteem than girls. On the other hand girls reported less alcohol use and abuse than boys.

\section{Structural equation modelling}

Prior to the specification and identification of the model a correlation and reliability analyses were conducted on the latent variables used in the structural model. Table 3 shows the

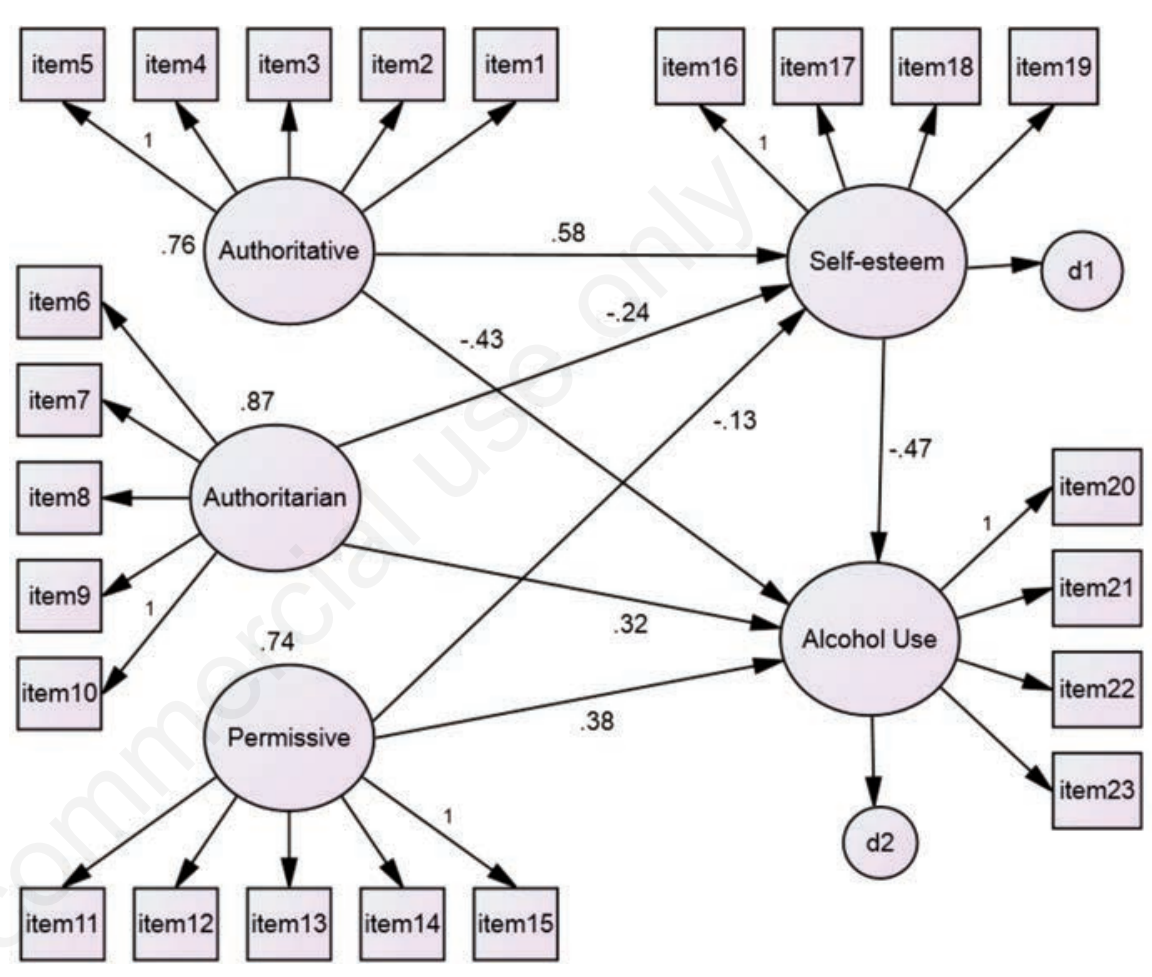

Figure 2. Hypothesised full structural equation model with standardized coefficients.

Table 2. Gender differences in self-esteem and alcohol use.

\begin{tabular}{lccccccccccc} 
& \multicolumn{4}{c}{ Self-esteem } & \multicolumn{4}{c}{ Alcohol use } & & \\
& M & SD & df & t & P & M & SD & df & $t$ & P \\
Male & 32.35 & 4.21 & 304 & 7.66 & $<0.05$ & 35.38 & 3.27 & 304 & 8.47 & $<0.01$ \\
Female & 32.02 & 3.64 & & & & 21.89 & 1.22 & & & \\
\hline
\end{tabular}

M, mean; SD, standard deviation.

Table 3. Correlation, reliability and descriptive statistics of latent constructs.

\begin{tabular}{lccccccc} 
& $\mathbf{1}$ & $\mathbf{2}$ & $\mathbf{3}$ & $\mathbf{4}$ & $\boldsymbol{\alpha}$ & $\mathrm{M}$ & SD \\
Self-esteem & - & & & & 0.83 & 19.26 & 2.84 \\
Authoritative & $0.42^{* *}$ & - & & & 0.86 & 23.46 & 0.89 \\
\hline Authoritarian & -0.26 & -0.08 & - & & 0.78 & 25.35 & 4.32 \\
Permissive & -0.14 & -0.12 & 0.21 & - & 0.74 & 19.87 & 2.74 \\
\hline Alcohol use & $-0.52^{* *}$ & $-0.21^{*}$ & 0.16 & 0.28 & 0.92 & 21.02 & 1.58 \\
\hline
\end{tabular}

$\mathrm{M}$, mean; SD, standard deviation. ${ }^{*} \mathrm{P}<0.05$, ${ }^{* *} \mathrm{P}<0.01$. 
correlation, reliability and descriptive statistics of the latent variables. After ensuring that the model is properly specified and identified, a CFA model was estimated using a Full Information Maximum Likelihood (FIML) estimation method by i) allowing all latent factors to vary freely; ii) fixing all factor variances to one; and iii) freeing all hypothesised factor loadings and constraining all others to zero. The model resulted in a $\chi^{2}(28)=32.53, \mathrm{P}>.05$; $\mathrm{CMIN} / \mathrm{DF}=1.77 ; \quad \mathrm{CFI}=0.99 ; \quad \mathrm{TLI}=0.98$; RMSEA $=0.02$ indicating that the hypothesised model has a good fit with the data. Accordingly, Figure 2 shows that authoritative parenting has a positive predictive effect on self-esteem $(\beta=0.58, \mathrm{P}<0.05)$ while authoritarian $(\beta=-$ $0.24, \quad \mathrm{P}<0.05)$ and permissive $(\beta=-0.13$, $\mathrm{P}>0.05$ ) patterns have negative predictive effect on self-esteem. In addition, authoritative pattern has a direct negative predictive effect on alcohol use $(\beta=-0.43, \mathrm{P}<0.05)$ while authoritarian $(\beta=0.32, \mathrm{P}<0.05)$ and permissive $(\beta=0.38, \mathrm{P}<0.05)$ patterns have direct positive predictive effects on alcohol use. Also, self-esteem was predictive of alcohol use $(\beta=-$ $0.47, \mathrm{P}<0.05)$.

\section{Discussion}

The purpose of this study was to explore the role of self-esteem and parenting patterns on alcohol use and abuse among adolescents. The hypothesised model had a good fit with the data.

\section{Gender, self-esteem and alcohol use and abuse}

It was found that boys engaged in more alcohol consumption than girls. This finding is consistent with that of previous research studies.23,24 Boys who have strong expectations that drinking will lead to social and physical pleasure and to sexual enhancement tend to drink more heavily, while girls who tend to drink more heavily are most often those who believe that alcohol mitigates the effects of stress.25 Alcohol consumption also relates to issues about social sanctions and disapproval where, for example, girls who drink regularly are met with more disapproval of their drinking than do boys and also girl's behaviour while intoxicated also tends to be met with more disapproval than the actions of boys. Interestingly, it was also found that boys reported higher self-esteem than girls, which according to literature on self-esteem and alcohol-use, girls would be expected to consume more alcohol than boys, but this was not the case in this study. This finding is however consistent with findings of previous research studies. ${ }^{26,27}$ Low self-esteem, almost invariably reported by girls, is essentially a matter that has to do with body image and physical appearance, adjusting to the onset of puberty, as well as interaction and relationship with their mothers. ${ }^{28}$ These psychosocial influences may partly account for the differences in alcohol consumption and self-esteem observed between boys and girls in the present study.

\section{Self-esteem, parenting patterns and alcohol-use and abuse}

It was found that authoritative parenting pattern was the most salient predictor of selfesteem followed by permissive and authoritarian parenting patterns respectively, which is consistent with findings of previous studies.5,6 This indicates that parenting patterns that involve warmth, demandingness and democracy are more likely to enhance the self-esteem of adolescents than parenting patterns that are grounded in the practice where the dominant mode of interaction is control on children that is sustained into adolescence and where there is minimal direction on children. Accordingly, children who feel that they are appreciated and respected by their parents are more likely to boldly engage their parents in fruitful discussions which would consequently enhance their self-esteem as they related with parents, siblings, friends, teachers and the larger society.

Again, unsurprisingly, it was found that authoritative parenting pattern had a significant negative effect on alcohol use while authoritarian parenting patterns had significant positive effects on alcohol use. This finding is also consistent with that of previous studies which found that the pattern of parental child-upbringing has a substantial influence on adolescent alcohol use and abuse.4,12,16 This suggests that children who are brought up with a parenting pattern that is undemocratic and overprotective are at increased risk of becoming a regular alcohol user or abuser. Adolescents perceive alcohol use to be a remedy for stress, especially emanating from parental practices, so at the least feeling of distress they resort to alcohol use as a way of coping with stress, ${ }^{29}$ but this is clearly a maladaptive way of coping with stress.

Also, while authoritative parenting pattern had a positive effect on self-esteem, authoritarian and permissive patterns had negative effects on self-esteem, albeit, the effect of permissive pattern was not significant. This suggests that, indeed, when parents open up to their children and allow their voices to be heard and acknowledged, it could greatly boost their self-esteem, which would consequently have positive health outcomes, including quitting alcohol use or abuse.

Finally, self-esteem was found to have a significant negative effect on alcohol use, suggesting that when self-esteem is high, alcohol use is low and vice versa. This finding is compatible with findings of previous studies that have found a negative association between self-esteem and alcohol-use and abuse. ${ }^{21,24,26}$ These previous studies have asserted variedly that low self-esteem is the underlying origin of many problem behaviours, and has a strong impact on alcohol use and abuse. This combi nation of findings provides some support for the conceptual premise that parenting patterns have a direct effect on alcohol use and abuse albeit it could do so indirectly through self-esteem, which could also have a direct effect on alcohol-use and abuse. Finally, within the socio-cultural setting of Ghana, even though authoritarian parenting pattern is the most widely reported parenting pattern, results of this study suggest that it is authoritative pattern that has shown to have the desirable effects on self-esteem and alcohol-use and abuse.

\section{Implications}

The broader implication of the findings of this study is an appeal to school authorities, teachers and especially parents and guardians to use effective child-rearing practices that would enhance the self-esteem and physical wellbeing of adolescents. The hypothesised model evaluated in this study is a practical heuristic strategy that can be used to identify the most effective and efficient parenting pattern that would enhance self-esteem to promote the adoption of healthy lifestyle, specifically regulated alcohol use. It would therefore be encouraging to see parents adopt a democratic pattern of parenting whereby adolescents would feel appreciated, involved and comfortable, which would in turn have a high tendency to boost their self-esteem. Selfesteem as has been demonstrated in this and in previous studies, has a substantial effect on whether or not adolescents would consume and abuse alcohol.

\section{Conclusions}

The items on the parenting authority questionnaire capture very critical aspects of parenting that gives a good indication of the salient patterns that are common in Ghana. Moreover, the use of structural equation modelling made it possible to combine empiricallyrelated variables into larger constructs thereby reducing measurement error and allowing for a more accurate assessment of the association between the various variables. This study is limited by the fact that only urban schools located in the Accra Metropolitan Assembly were considered. Therefore, with a small sample size, caution must be applied, as the findings might not be transferable to the whole of Ghana. Nonetheless, the location of the study, Accra, represents salient characteristics that 
imbue the general characteristics of Ghana making the findings quite extrapolatable. Psychosocial variables such as religion and cultural beliefs may have some influence on parenting patterns, thus future studies could consider them.

\section{References}

1. American Academic of Child and Adolescent Psychiatry. Teens: alcohol and other drugs. Available from: http://www.aacap.org/AACAP/Families_and _Youth/Facts_for_Families/Facts_for_Fa milies_Pages/Teens_Alcohol_And_Other_ Drugs_03.aspx.

2. Gelder M, Mayou R, Geddes J. Psychiatry. USA: Oxford University Press; 2005.

3. Bonomo Y, Coffey C, Wolfe R, et al. Adverse outcomes of alcohol use in adolescents. Addiction 2001;96:1485-96.

4. Baumrind D. The influence of parenting style on adolescents' competence and substance use. J Early Adolescents 1991;11:56-95.

5. Baumrind D. Socialization determinants of personal agency. Paper presented at the meeting of the society for Research in Child Development, New Orleans; 1977.

6. Maccoby EE, Martin JA. Socialization in the context of the family: parent-child interaction. In: Mussen PH, Hetherington EM, eds. Handbook of child psychology. Vol. 4. Socialization, personality, and social development. 4th ed. Hoboken: John Wiley \& Sons, Inc.; 1983. pp 1-101.

7. Tilman KH. Non-traditional siblings and the academic outcomes of adolescents. Soc Sci Res 2008;37:88-108.

8. Steinberg L, Darling N, Fletcher AC. Authoritative parenting and adolescent adjustment: An ecological journey. In Moen P, Elder GH J., Luscher K, eds. Examining lives in context: perspectives on the ecology of human development. Washington, DC: American Psychological Association. 1995. pp 423-466.

9. Barber BK. Parental psychological control: revisiting a neglected construct. Child Dev 1996;6:3296-319.

10. Visser L, de Winter AF, Vollebergh WAM, Verhuls FC. The impact of parenting styles on adolescent alcohol use: the TRAILS study. Eur Addict Res 2013;19:165-72.

11. Cohen DA, Richardson J, LaBree L. Parenting behaviors and the onset of smoking and alcohol use: a longitudinal study. Pediatrics 1994;94:368-75.

12. Jackson L, Henricksen L, Foshee V. Alcohol-specific socialization, patenting behaviours and alcohol use by children. $\mathrm{J}$ Stud Alcohol Drugs 1998;60:362-67.

13. Huitt W. Self-concept and self-esteem. Educational psychology interactive. Valdosta: Valdosta State; 2004.

14. Rosenberg M. Conceiving the self. New York: Basic Books; 1979.

15. Anderson JA, Olnhausen KS. Adolescent self-esteem: a foundational disposition. Nurs Sci Quart 1999;12:62-7.

16. DeHart T, Tennen H, Armeli S, et al. A Diary study of implicit self-esteem, interpersonal interactions and alcohol consumption in college students. J Exp Soc Psychol 2009;45:720-30.

17. Maldonado MR, Pedrão LJ, Castillo AMM, et al. Self-esteem, perceived self-efficacy, consumption of tobacco and alcohol in secondary students from urban and rural areas of Monterrey, Nuevo León, México. Rev Latino-Am Enfermagem 2008;16:61420.

18. Buri J. Parental authority questionnaire. J Pers Assess 1991;57:110-19.

19. Sim HO. Coping resources mediating the relationship between stressful life events and delinquent behavior among adolescents. Doctoral Dissertation, Oregon State University; 1994.

20. Saunders JB, Aasland OG, Babor TF, et al.
Development of the alcohol use disorders identification test (AUDIT): WHO collaborative project on early detection of persons with harmful alcohol consumption. II. Addiction 1993;88:791-804.

21. Saunders JB, Aasland OG, Amundsen A, Grant M. Alcohol consumption and related problems among primary health care patients: WHO collaborative project on early detection of persons with harmful alcohol consumption I. Addiction 1993;88:349-62.

22. Byrne BM. Structural equation modelling with amos: basic concepts applications, and programming. 2nd Ed. New York: Routledge; 2010.

23. Berger BD, Adesso VJ. Gender differences in using alcohol to cope with depression. Addict Behav 1991;16:315-27.

24. Nolen-Hoeksema S. Gender differences in risk factors and consequences for alcohol use and problems. Clin Psychol Rev 2004;24:981-1010.

25. Western Washington University. Alcohol 101. Counselling, health, and wellness services. Available from: http://www.wwu.edu/chw/preventionandwellness/pdfs/GenderDifferences.pdf

26. Kling KC, Hyde JS, Showers CJ, Buswell BN. Gender differences in self-esteem: a meta-analysis. Psychol Bull 1999;125:470500.

27. Tamini BK, Valibeygi R. The impact of gender, age and academic branch on selfesteem of students. J Basic Applied Sci Res 2011;1:1065-69.

28. Marcotte D, Fortin L, Potvin P, Papillion M. Gender differences in depressive symptoms during adolescence: role of gendertyped characteristics, self-esteem, body image, stressful life events, and pubertal status. J Emot Behav Disord 2002;10:2943.

29. Lovallo WR. Stress and health: biological and physiological interactions. Thousand Oaks: Sage Publications; 2005. 